\title{
Synthesis and Optimization of Deesterified Acacia-Alginate Nanohydrogel for Amethopterin Delivery
}

\author{
T. Sathish (iD, ${ }^{1}$ N. Sabarirajan, ${ }^{2}$ S. Prasad Jones Christydass, ${ }^{3}$ S. Sivananthan, ${ }^{4}$ \\ R. Kamalakannan, ${ }^{5}$ V. Vijayan (iD, ${ }^{4}$ and Prabhu Paramasivam (iD) \\ ${ }^{1}$ Department of Computer Science and Engineering, Saveetha School of Engineering, SIMATS, Chennai 602105, \\ Tamil Nadu, India \\ ${ }^{2}$ Department of Mechanical Engineering, Chendhuran College of Engineering and Technology, Pudukkottai, \\ Tamil Nadu, India \\ ${ }^{3}$ Department of Electrical and Electronics Engineering, K. Ramakrishnan College of Technology, Tiruchirapalli, \\ Tamil Nadu, India \\ ${ }^{4}$ Department of Mechanical Engineering, K.Ramakrishnan College of Engineering, Samayapuram, Tiruchirapalli, \\ Tamil Nadu, India \\ ${ }^{5}$ Department of Mechanical Engineering, M. Kumarasamy College of Engineering, Karur, Tamil Nadu, India \\ ${ }^{6}$ Department of Mechanical Engineering, College of Engineering and Technology, Mettu University, Metu 318, Ethiopia
}

Correspondence should be addressed to Prabhu Paramasivam; drprabhu@meu.edu.et

Received 8 November 2021; Revised 4 January 2022; Accepted 18 January 2022; Published 11 February 2022

Academic Editor: Valeria De Matteis

Copyright $\odot 2022$ T. Sathish et al. This is an open access article distributed under the Creative Commons Attribution License, which permits unrestricted use, distribution, and reproduction in any medium, provided the original work is properly cited.

Naturally obtained materials are preferable for the production of biomedicine in biomedical applications. Acacia gum is has recently become a hopeful one in the biomedicine production due to its excellent properties, namely, emulsifier, stabilizing mediator, suspending agent, etc. In this novel work, we synthesised and characterized the deesterified Acacia gum-alginate nanohydrogel (DEA-AG NPs) as a carrier for amethopterin (ATN) delivery. This combination is used in the drug effectiveness and tissue engineering. In this work, the Taguchi route is implemented for estimating of particle size and zeta potential (mV) through optimization. Following three parameters are considered for this work: DEA solution concentration $(0.008,0.016,0.024$, and $0.032 \mathrm{w} / \mathrm{v} \%)$, alginate molecular weight $(3,6,9$, and $12 \mathrm{MW})$, and ATN/DEA ratio $(1: 4,1: 8,1: 12$, and $1: 16 \mathrm{w} / \mathrm{w} \%)$. In particle size analysis and zeta potential analysis, the DEA solution concentration is highly influenced. Minimum particle size is found as $148.50 \mathrm{~nm}$. Similarly, maximum zeta potential is identified as $29.5 \mathrm{mV}$.

\section{Introduction}

In the paramedical application the drug delivery is one of the fast-growing technologies for cancer nanotherapeutics. This technology considers nanoparticles as a controlled liberate reservoirs. Further, it can eradicate the restrictions of traditional cancer therapy [1]. The use of nanoparticles in cancer nanotherapeutics improves cellular systems, reduces side effects, and controls tumour development [2-4]. In cancer nanotherapeutics, some problems are raised due to the nanoparticle's size and stability in the physiological function.
Several nanoparticles are involved in the drug delivery system. Of all of them, the nanohydrogels are the most excellent and potential ones in the drug delivery system [5]. Better porous molecular formation, elevated hydrophilicity, and small size of nanogels are the considerable advantages of the nanohydrogels [6-8]. Nanohydrogels are effectively utilized in the drug delivery system both in active and passive conditions. The structural properties of nanohydrogels vary in medical and pharmaceutical applications, and the production of polymers is dependent on these structural properties [9-11]. The excellent biocompatibility of nanohydrogels based on water molecules is vastly used in medical and pharmaceutical appliances [12]. The 
massive characteristics of the nanoparticles and the high advantages of the hydrogel amalgamation are hopeful in the drug delivery system.

Acacia is one of the natural gums and has excellent properties, being highly soluble in water [13]. It controls the cholesterol levels and also assists to increase weight loss. Further improvement of the Acacia solubility nature was achieved by conducting deesterified Acacia (DFA). Continually, the DFA highly influenced to prepare the hydrogels with the addition of using positively charged polymers such as alginate [14-16]. Alginate is one of the anionic polymers. It possesses various properties such as high biocompatibility in nature, low toxicity, minimum cost, form a gentle gelation, bacteriostatic, and anticholesteremic [17, 18]. Alginate is one of the powder materials; it comprises sodium alginate, calcium sulphate, trisodium phosphate, diatomaceous earth, zinc oxide, and potassium titanium fluoride [19]. All these elements are mixed homogeneously in water to form a smooth gel to create a mold [20].

The present investigation focused on to prepare the Acacia gum-alginate nanoparticles (DEA-AG NPs) to hold the amethopterin (ATN) is produced by the coacervation method [21]. We hope that the DEA-AG nanohydrogel is one of the appropriate drug delivery systems in medical applications and tissue engineering [22]. Taguchi statistical analysis is incorporated into this experimental work to analyze the effects of parameters on the particle size and zeta potential $(\mathrm{mV})$ of the nanohydrogel [23].

\section{Materials and Methods}

The Acacia gum is procured from Opera Chemisol India Private Limited, Chennai. Alginate powder ( 5 and $10 \mathrm{kDa})$ is purchased from the Kwality Chemicals Co., Valipalayam, Coimbatore. The remaining chemical items are procured from the Praxor Instruments and Scientific Co., Chennai. This experimental work considered the Taguchi analysis to optimize the parameters and also found the parameters' effects on the quality of the responses [24]. Orthogonal Array L16 is taken for conducting of parameters optimization in the preparation of nanaohydrogel and its properties [25]. ANOVA analysis is also conducted for evaluation of the parameter contribution in the particle size analysis as well as zeta potential analysis [26]. Minitab 18 statistical software is used for analyzing of parameters optimization and control of the $\mathrm{S} / \mathrm{N}$ ratio in the experimental work. Three parameters and four levels are accounted for this experimental work, and it is presented in Table 1.

2.1. Experimental Procedure. In this work, the DEA is prepared by using the deesterification process of Acacia gum, as shown in Figure 1. The DEA is liquefied in the deionized water to obtain the different concentrations of DFA solution such as $0.008 \mathrm{w} / \mathrm{v} \%, 0.016 \mathrm{w} / \mathrm{v} \%, 0.024$, w $/ \mathrm{v}$ $\%$, and $0.032 \mathrm{w} / \mathrm{v} \%$. Furthermore, different molecular weights $(3,6,9$, and $12 \mathrm{kDa})$ of the alginate powder are taken and dissolved in deionized water and $1 \mathrm{v} / \mathrm{v} \%$ acetic acid combination solution [27-29]. After dissolving the alginate in the combined solution, it can be formed into the $0.4 \%$ (w/ v) concentration of each solution effectively. Continually, the ATN solution is diluted with deionized water properly and receives the $2 \%(\mathrm{v} / \mathrm{v})$ ATN solution [30-32]. The combination of ATN/DEA solution is achieved by the effect of stirring action using a magnetic stirrer. The blending of ATN-DEA solutions is considered at the ratios of $1: 4,1: 8$, $1: 12$, and $1: 16(\mathrm{w} / \mathrm{w})$. The alginate solutions with various molecular weights are mixed with the ATN-DEA solution drop by drop. The stirring process is conducted for $20 \mathrm{~min}$ at atmospheric temperature for the prepared nanoparticles. Further a centrifuge process is conducted for $30 \mathrm{~min}$ at $18000 \mathrm{rpm}$ [33]. Finally, the nanoparticles are precipitated.

The response values of particle size and zeta potential of the nanohydrogels are carried out by using of DLS (sizing), M3-PALS (zeta potential) equipment [34]. Initially, the precipitated nanohydrogel was dispersed in $1 \mathrm{ml}$ of deionized water and all the readings were taken by using a $4 \mathrm{~mW}$ $\mathrm{HeNe}$ laser of $633 \mathrm{~nm}$ wavelength at $25^{\circ} \mathrm{C}$. Finally, the consideration of the L16 array all the experiments are conducted.

\section{Results and Discussion}

Table 2 presents the entire experimental summary and output response of the particle size analysis and zeta potential analysis. The minimum particle size was recorded as $148.50 \mathrm{~nm}$ by the influence of $0.008 \mathrm{w} / \mathrm{v} \%$ DEA solution concentration, 3 molecular weight of alginate, and 1:4 of w/ $\mathrm{w} \%$ ATN/DEA ratio. On the contrary, the maximum particle size was registered as $439.04 \mathrm{~nm}$. In the zeta potential analysis, the maximum zeta potential was observed as $29.5 \mathrm{mV}$ by involving of $0.032 \mathrm{w} / \mathrm{v} \%$ DEA solution concentration, 3 molecular weight of alginate, and $1: 16$ of w/w $\%$ ATN/DEA ratio. The minimum zeta potential was observed as $20.5 \mathrm{mV}$.

3.1. Particle Size Analysis. Table 3 is the output of Taguchi analysis in which the DEA solution concentration is found to be better at level 1 as it offers a smaller mean particle size of $193.8 \mathrm{~nm}$. In the case of alginate molecular weight, level three was the level that offered a minimum average particle size of $256.9 \mathrm{~nm}$. For the ATN/DEA ratio factor, level 1 was found to be better as it offered a minimum mean particle size of $250.7 \mathrm{~nm}$.

From Table 4, it is understood that the higher the signal (favourable response), the better. Table 4 also contains the output of Taguchi analysis in terms of signal-to-noise ratio. The factor DEA solution concentration was found to be better at level 1 as it offered a high signal-to-noise ratio of $(-45.59)$ for the minimum particle size. In the case of alginate molecular weight, level three was found to be better as it offered a high signal-to-noise ratio of $(-47.87)$ for the minimum particle size. For the ATN/DEA ratio factor, level 1 was found to be better as it offered a high signal-to-noise ratio of $(-47.44)$ for the minimum particle size.

Figure 2 illustrates the main effects plot for mean and the $\mathrm{S} / \mathrm{N}$ ratio of the particle size response. Figure 2(a) shows the 
Table 1: Process parameters and their levels for Taguchi L16 experimental design.

\begin{tabular}{|c|c|c|c|c|c|}
\hline S. no. & Parameters & Level 1 & Level 2 & Level 3 & Levels 4 \\
\hline 1 & DEA solution concentration (w/v \%) & 0.008 & 0.016 & 0.024 & 0.032 \\
\hline 2 & Alginate molecular weight (MW) & 3 & 6 & 9 & 12 \\
\hline 3 & ATN/DEA ratio (w/w \%) & $1: 4$ & $1: 8$ & $1: 12$ & $1: 16$ \\
\hline
\end{tabular}

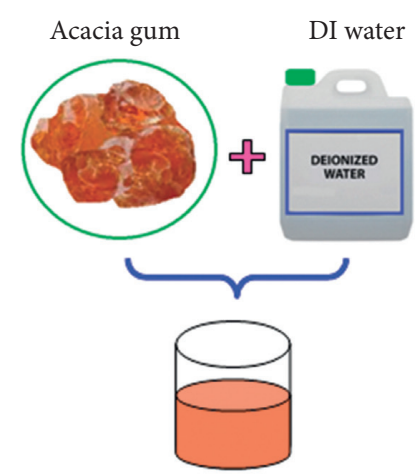

DEA solution De-esterification of Acacia gum

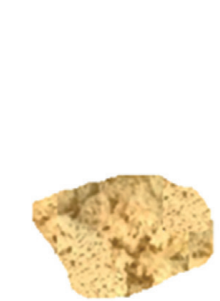

Acacia-Alginate nano-hydrogel

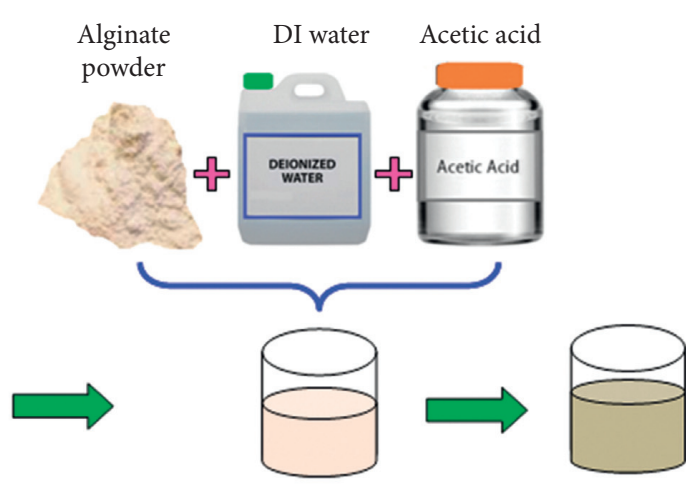

ATN solution

FIGURE 1: Flow process of acacia-alginate nanohydrogel formation.

TABLE 2: Experimental process parameters and response summary of nanohydrogel preparation.

\begin{tabular}{|c|c|c|c|c|c|c|c|}
\hline $\begin{array}{l}\text { Exp. } \\
\text { runs }\end{array}$ & $\begin{array}{c}\text { DEA solution } \\
\text { concentration }(w / v \%)\end{array}$ & $\begin{array}{c}\text { Alginate molecular } \\
\text { weight }(\mathrm{MW})\end{array}$ & $\begin{array}{c}\mathrm{ATN} / \mathrm{DEA} \\
\text { ratio }(\mathrm{w} / \mathrm{w} \%) \\
\end{array}$ & $\begin{array}{l}\text { Particle size } \\
(\mathrm{nm})\end{array}$ & $\begin{array}{l}\text { Zeta potential } \\
(\mathrm{mV})\end{array}$ & $\begin{array}{l}\mathrm{S} / \mathrm{N} \text { ratio of } \\
\text { size }\end{array}$ & $\begin{array}{c}\mathrm{S} / \mathrm{N} \text { ratio of zeta } \\
\text { potential }\end{array}$ \\
\hline 1 & 0.008 & 3 & $1: 4$ & 148.50 & 20.5 & 43.4345 & 26.2351 \\
\hline 2 & 0.008 & 6 & $1: 8$ & 180.64 & 22.3 & 45.1363 & 26.9661 \\
\hline 3 & 0.008 & 9 & $1: 12$ & 250.70 & 24.6 & 47.9831 & 27.8187 \\
\hline 4 & 0.008 & 12 & $1: 16$ & 195.28 & 27.2 & 45.8132 & 28.6914 \\
\hline 5 & 0.016 & 3 & $1: 8$ & 300.12 & 26.8 & 49.5459 & 28.5627 \\
\hline 6 & 0.016 & 6 & $1: 4$ & 354.17 & 27.9 & 50.9842 & 28.9121 \\
\hline 7 & 0.016 & 9 & $1: 16$ & 211.34 & 23.6 & 46.4996 & 27.4582 \\
\hline 8 & 0.016 & 12 & $1: 12$ & 408.97 & 28.4 & 52.2338 & 29.0664 \\
\hline 9 & 0.024 & 3 & $1: 12$ & 412.07 & 28.9 & 52.2994 & 29.2180 \\
\hline 10 & 0.024 & 6 & $1: 16$ & 325.78 & 26.7 & 50.2585 & 28.5302 \\
\hline 11 & 0.024 & 9 & $1: 4$ & 187.34 & 22.4 & 45.4526 & 27.0050 \\
\hline 12 & 0.024 & 12 & $1: 8$ & 267.58 & 24.9 & 48.5491 & 27.9240 \\
\hline 13 & 0.032 & 3 & $1: 16$ & 439.04 & 29.5 & 52.8501 & 29.3964 \\
\hline 14 & 0.032 & 6 & $1: 12$ & 425.18 & 28.6 & 52.5715 & 29.1273 \\
\hline 15 & 0.032 & 9 & $1: 8$ & 378.19 & 25.2 & 51.5542 & 28.0280 \\
\hline 16 & 0.032 & 12 & $1: 4$ & 312.67 & 26.4 & 49.9017 & 28.4321 \\
\hline
\end{tabular}

graphical representation of Table 3 (mean particle size responses), and Figure 2(b) demonstrates the graphical representation of Table 4 (favourable chances signal-to-noise ratio). The purpose of this graph is to exhibit the optimal process factors which support the research objective. This analysis aims to reduce the average particle size. Figure 2(a) for the factor a DEA solution concentration level 1 (0.008) shows the minimum mean particle size response. Similarly, 
TABLe 3: Mean particle size responses with respect to process parameters and their levels.

\begin{tabular}{lccc}
\hline Level & DEA solution concentration $(w / v)$ & Alginate molecular weight $(\mathrm{MW})$ & ATN/DEA ratio $(\mathrm{w} / \mathrm{w}$ \%) \\
\hline 1 & 193.8 & 324.9 & 250.7 \\
2 & 318.6 & 321.4 & 281.6 \\
3 & 298.2 & 256.9 & 374.2 \\
4 & 388.8 & 296.1 & 292.9 \\
Delta & 195.0 & 68.0 & 123.6 \\
Rank & 1 & 3 & 2 \\
\hline
\end{tabular}

TABLE 4: Signal-to-noise ratio for particle size responses with respect to process parameters and their levels, the smaller the better.

\begin{tabular}{lccc}
\hline Level & DEA solution concentration (w/v \%) & Alginate molecular weight (MW) & ATN/DEA ratio (w/w \%) \\
\hline 1 & -45.59 & -49.53 & -47.44 \\
2 & -49.82 & -49.74 & -48.70 \\
3 & -49.14 & -47.87 & -51.27 \\
4 & -51.72 & -49.12 & -48.86 \\
Delta & 6.13 & 1.87 & 3.83 \\
Rank & 1 & 3 & 2 \\
\hline
\end{tabular}

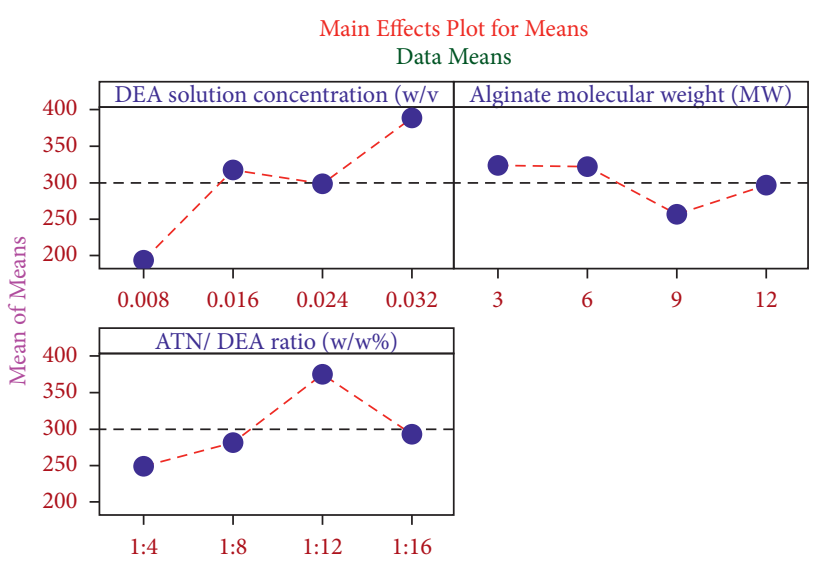

(a)

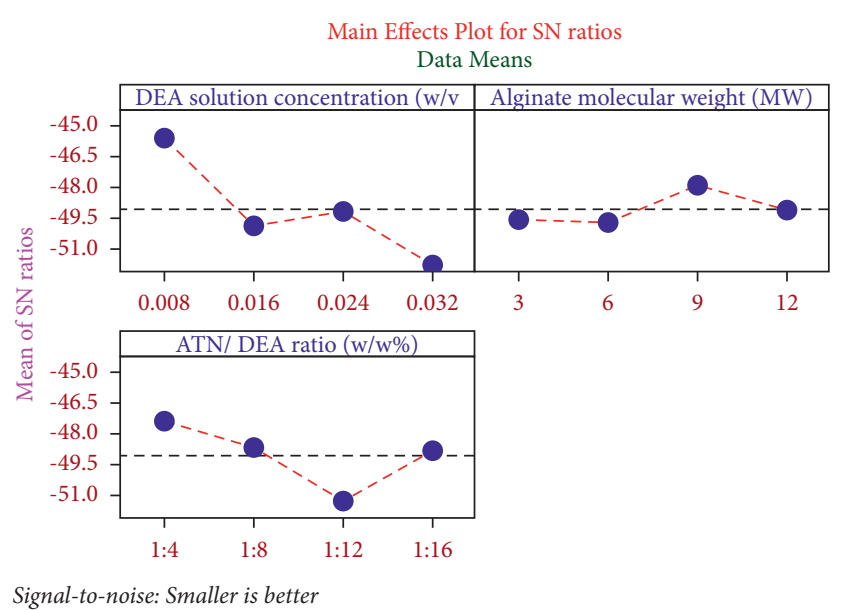

(b)

FIGURE 2: Main effects plot for (a) mean of particle size and (b) S/N ratio of particle size.

Figure 2(b) shows the maximum favourable chances (signal to noise ratio) at level 1 which is $0.008 \mathrm{w} / \mathrm{v} \%$. Hence, it is concluded that for the factor, a DEA solution concentration of $0.008 \mathrm{w} / \mathrm{v} \%$ is optimal. Similarly, for the factor of alginate molecular weight, level 3 is found optimal, as Figures 2(a) and 2(b) show minimal mean particle size and maximum favourable chance ( $\mathrm{S} / \mathrm{N}$ ratio) at level 3 as $9 \mathrm{MW}$, respectively, and for the factor ATN/DEA ratio, the graphs at Figure 2(a) show minimum average particle size at level 1 as well as Figure 2(b) also indicates a higher signal-to-noise ratio at level 1 as $1: 4 \mathrm{w} / \mathrm{w} \%$. Hence, the optimal process parameters or optimal input factors for obtaining the minimal mean particle size are $0.008 \mathrm{w} / \mathrm{v} \%$ DEA solution concentration, $9 \mathrm{MW}$ alginate, and a 1:4 of w/w \% ATN/ DEA ratio.

Minimum particle size was observed by the influence of $0.008 \mathrm{w} / \mathrm{v} \%$ of DEA solution concentration, further increasing of DEA solution concentration the particle size also increased. A minimum level of alginate (MW) produced a maximum particle size; $9 \mathrm{MW}$ of alginate offered a minimum particle size. In the ATN/DEA ratio parameter analysis, the minimum particle size was observed by the influence of a 1:4 ratio of ATN/DEA. All the data points were scattered uniformly and within the limit it was clearly exposed in the probability plot, as shown in Figure 3. In this experimental work, the chosen parameters of the acacia-alginate nanohydrogel for amethopterin delivery and the executed statistical model were appropriate ones.

Table 5 presents the ANOVA analysis for particle size; in this analysis, we point out the parameter contribution based on the $F$ value. Among the three parameters, a higher contribution of $55.16 \%$ was observed by the influence of DEA solution concentration followed by $23.55 \%$ of the ATN/DEA ratio and $8.33 \%$ of alginate molecular weight. It is clearly noted that the DEA solution concentration changed 


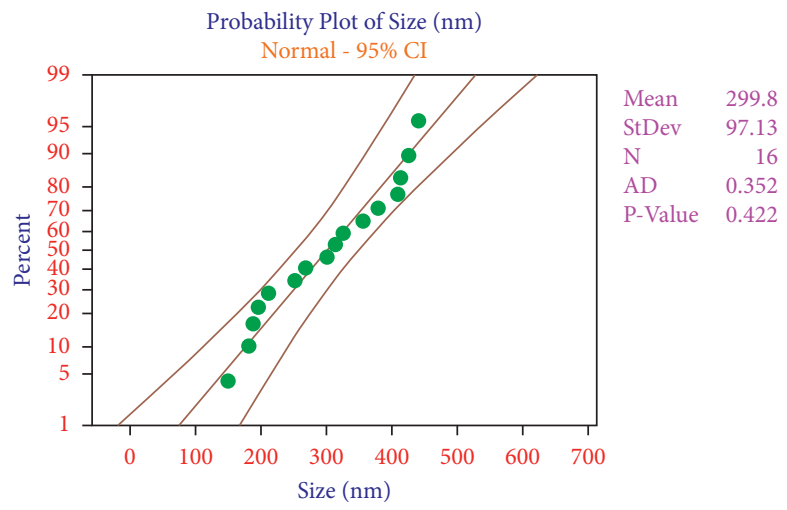

Figure 3: Probability plot for particle size.

TABle 5: Analysis of variance for particle size.

\begin{tabular}{|c|c|c|c|c|c|c|c|}
\hline Source & $\mathrm{DF}$ & Seq SS & Contribution (\%) & Adj SS & Adj MS & $F$ value & $P$ value \\
\hline DEA solution concentration ( $\mathrm{w} / \mathrm{v} \%)$ & 3 & 78055 & 55.16 & 78055 & 26018 & 8.53 & 0.014 \\
\hline Alginate molecular weight (MW) & 3 & 11818 & 8.35 & 11818 & 3939 & 1.29 & 0.030 \\
\hline ATN/DEA ratio $(w / w \%)$ & 3 & 33327 & 23.55 & 33327 & 11109 & 3.64 & 0.023 \\
\hline Error & 6 & 18308 & 12.94 & 18308 & 3051 & & \\
\hline Total & 15 & 141509 & 100.00 & & & & \\
\hline
\end{tabular}

the results of the particle size. $P$ value of the all parameters were significantly sufficient, it can be noted that the $P$ values were less than 0.05 .

3.2. Regression Equation. Size $(\mathrm{nm})=299.8-106.1$ DEA solution concentration (w/v\%) $0.008+18.8$ DEA solution concentration (w/v \%) 0.016-1.7 DEA solution concentration (w/v \%) $0.024+88.9$ DEA solution concentration (w/v \%) $0.032+25.1$ alginate molecular weight (MW) $3+21.6$ alginate molecular weight (MW) 6-43.0 alginate molecular weight (MW) 9-3.7 alginate molecular weight (MW) 12-49.2 ATN/DEA ratio (w/w \%) $1: 4-18.2$ ATN/DEA ratio (w/w \%) $1: 8+74.4$ ATN/DEA ratio (w/w \%) $1: 12-7.0$ ATN/DEA ratio (w/w \%) $1: 16$.

Figure 4 represents the correlations of two parameters' influence with the assist of a 3D trajectory plot. Figure 4(a) illustrates the relations between DEA solution concentration and alginate molecular weight. From this analysis, the minimum particle size was observed by involving $0.008 \mathrm{w} / \mathrm{v}$ $\%$ DEA solution concentration and 3 molecular weights of alginate. Figure 4(b) presents the correlations of alginate molecular weight and ATN/DEA ratio, minimum particle size was observed by the influence of $3 \mathrm{MW}$ of alginate and a $1: 4$ ATN/DEA ratio. Figure 4(c) illustrates the correlation between the ATN/DEA ratio and DEA solution concentrations. ATN/DEA ratio of $1: 4$ and $0.008 \mathrm{w} / \mathrm{v} \%$ DEA solution concentration offered the minimum particle size.

3.3. Zeta Potential Analysis. Tables 6 and 7 represent the mean and $\mathrm{S} / \mathrm{N}$ ratio of the zeta potential analysis. In this analysis, the DEA solution concentration was extremely influenced by the ATN/DEA ratio and alginate molecular weight.
Table 6 shows the output of Taguchi analysis for optimizing the process factors for maximizing zeta potential response. In Table 6, level 4 was found optimal for the DEA solution concentration as it offered a maximum mean particle size of $27.42 \mathrm{mV}$. In the case of alginate molecular weight, level 4 was the level that offered a higher average zeta potential response of $26.73 \mathrm{mV}$. For the ATN/DEA ratio factor, level 3 was found to be better as it offered a maximum mean zeta potential response of $27.63 \mathrm{mV}$.

It can be understood from Table 7 that the higher the signal (favourable response), the better. Table 4 also shows the output of Taguchi analysis in terms of signal-to-noise ratio. The factor DEA solution concentration was found to be better at level 4 as it offered a high signal-to-noise ratio of (28.75) for maximum zeta potential. In the case of alginate molecular weight, level 4 was found to be better as it offered a high signal-to-noise ratio of (28.53) for maximum zeta potential. For the ATN/DEA ratio factor, level 3 was found to be better as it offered a high signal-to-noise ratio of (28.81) for maximum zeta potential.

Optimal parameters of the zeta potential analysis were achieved as the following: $0.032 \mathrm{w} / \mathrm{v} \%$ DEA solution concentration, 12 molecular weight of alginate, and $1: 12$ of w/w $\%$ ATN/DEA ratio.

Figure 5 reveals the main effects plot for the means and $\mathrm{S} / \mathrm{N}$ ratio of the zeta potential analysis. A higher DEA solution concentration $(0.032 \mathrm{w} / \mathrm{v} \%)$ offered maximum zeta potential values. DEA solution concentration increases the zeta potential values of the nanaohydrogel. Increasing of alginate molecular weight increases the zeta potential analysis.

Figure 5 demonstrates that the main effects plot for means and $\mathrm{S} / \mathrm{N}$ ratio of the zeta potential response. Figure 5(a) shows the graphical representation of Table 6 (mean zeta potential 


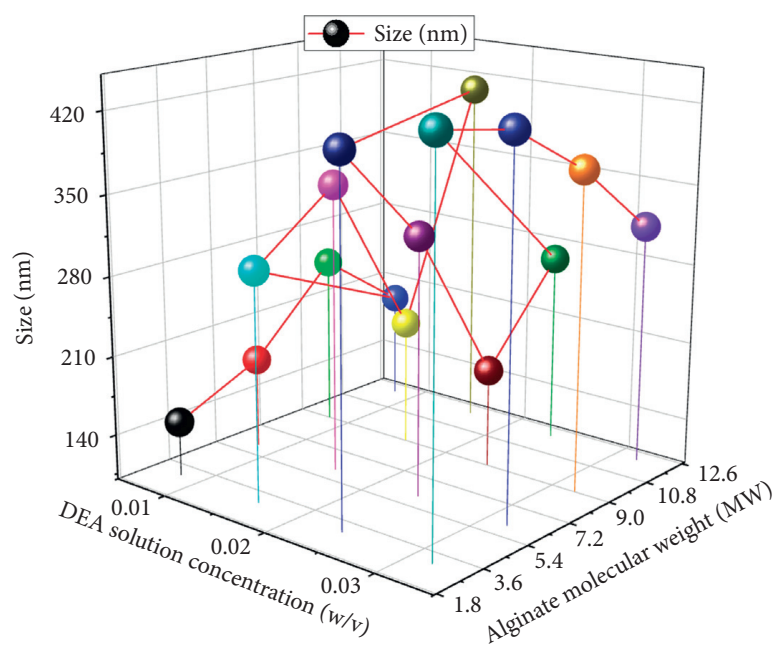

(a)

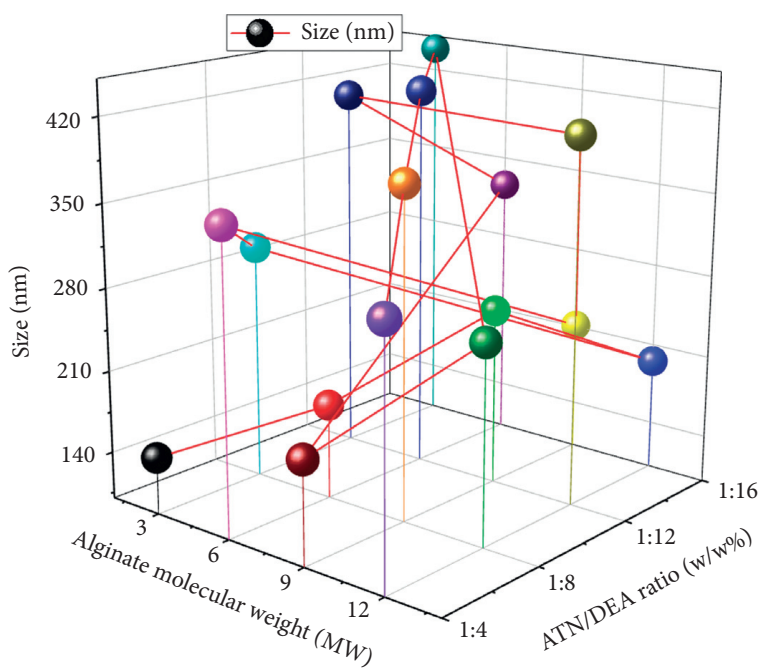

(b)

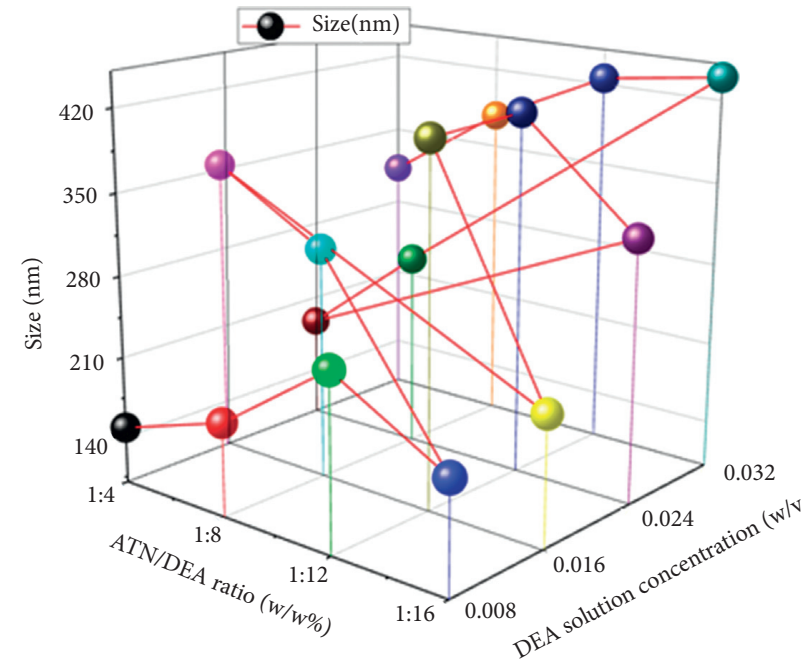

(c)

FIGURE 4: 3D trajectory plot analysis for particle size effects with the combination of factors: (a) DEA solution concentration and alginate molecular weight, (b) alginate molecular weight and ATN/DEA ratio, and (c) ATN/DEA ratio and DEA solution concentration.

TABLE 6: Mean of zeta potential responses with respect to process parameters and their levels.

\begin{tabular}{lccc}
\hline Level & DEA solution concentration (w/v \%) & Alginate molecular weight (MW) & ATN/DEA ratio (w/w \%) \\
\hline 1 & 23.65 & 26.42 & 24.30 \\
2 & 26.68 & 26.38 & 24.80 \\
3 & 25.73 & 23.95 & 27.63 \\
4 & 27.42 & 26.73 & 26.75 \\
Delta & 3.77 & 2.78 & 3.33 \\
Rank & 1 & 3 & 2 \\
\hline
\end{tabular}

TABLE 7: Signal-to-noise ratio of zeta potential responses with respect to process parameters and their levels, the larger the better.

\begin{tabular}{lccc}
\hline Level & DEA solution concentration (w/v \%) & Alginate molecular weight (MW) & ATN/DEA ratio (w/w \%) \\
\hline 1 & 27.43 & 28.35 & 27.65 \\
2 & 28.50 & 28.38 & 27.87 \\
3 & 28.17 & 27.58 & 28.81 \\
4 & 28.75 & 28.53 & 28.52 \\
Delta & 1.32 & 0.95 & 1.16 \\
Rank & 1 & 3 & 2 \\
\hline
\end{tabular}




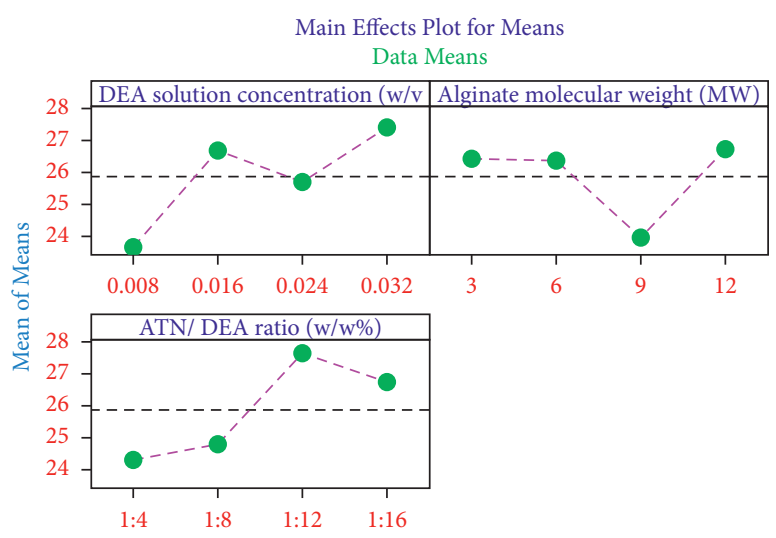

(a)

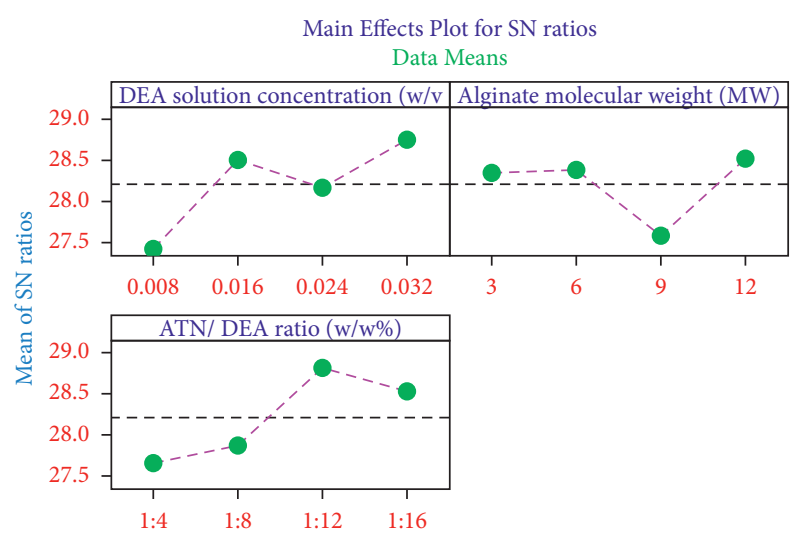

Signal-to-noise: Larger is better

(b)

FIGURE 5: Main effects plot for (a) mean of zeta potential and (b) $\mathrm{S} / \mathrm{N}$ ratio of zeta potential.

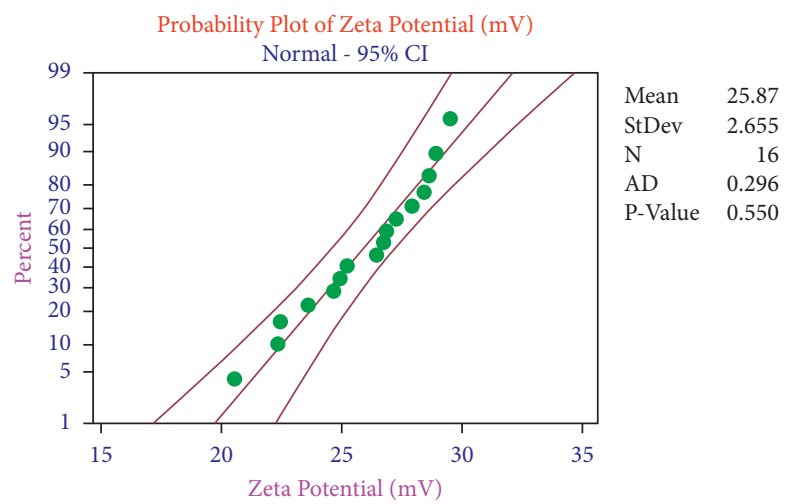

Figure 6: Probability plot for zeta potential.

TABLE 8: Analysis of variance for zeta potential.

\begin{tabular}{|c|c|c|c|c|c|c|c|}
\hline Source & DF & Seq SS & Contribution (\%) & Adj SS & Adj MS & $F$ value & $P$ value \\
\hline DEA solution concentration (w/v \%) & 3 & 32.06 & 30.33 & 32.06 & 10.687 & 2.69 & 0.010 \\
\hline Alginate molecular weight (MW) & 3 & 19.92 & 18.85 & 19.92 & 6.641 & 1.67 & 0.021 \\
\hline ATN/DEA ratio $(w / w \%)$ & 3 & 29.86 & 28.24 & 29.86 & 9.952 & 2.50 & 0.046 \\
\hline Error & 6 & 23.87 & 22.58 & 23.87 & 3.979 & & \\
\hline Total & 15 & 105.71 & 100.00 & & & & \\
\hline
\end{tabular}

responses), and Figure 5(b) demonstrates the graphical representation of Table 7 (favourable chances Signal to Noise Ratio). The purpose of this graph is to exhibit the optimal process factors which support the research objective. This analysis aims to reduce the average zeta potential. In Figure 5(a) for the factor, a DEA solution concentration at level 4 (0.032) shows the maximum mean zeta potential response. Similarly, Figure 5(b) shows the maximum favourable chances (signal-to-noise ratio) at level 4 which is $0.032 \mathrm{w} / \mathrm{v} \%$. Hence, it is concluded that for the factor a DEA solution concentration $0.032 \mathrm{w} / \mathrm{v} \%$ is optimal. Similarly, for the factor of alginate molecular weight, level 4 is found optimal as Figures 5(a) and 5(b) show maximum mean zeta potential and maximum favourable chance $(\mathrm{S} / \mathrm{N}$ ratio) at level
4 as $12 \mathrm{MW}$, respectively, and for the factor ATN/DEA ratio, the graphs at Figure 5(a) show maximum average zeta potential at level 3 as well as Figure 5(b) also indicates a higher signal-to-noise ratio at level 3 as $1: 16 \mathrm{w} / \mathrm{w} \%$. Hence, the optimal process parameters or optimal input factors for obtaining the maximum zeta potential are $0.032 \mathrm{w} / \mathrm{v} \%$ DEA solution concentration, $12 \mathrm{MW}$ molecular weight of alginate, and $1: 16$ of $\mathrm{w} / \mathrm{w} \%$ ATN/DEA ratio.

In the zeta potential analysis, all the data points were distributed evenly and within the limit, as shown in Figure 6. Based on the data points distribution, the selected parameters and the model were good ones.

Table 8 presents the parameters' contributions in the zeta potential analysis; influence of contribution was estimated 


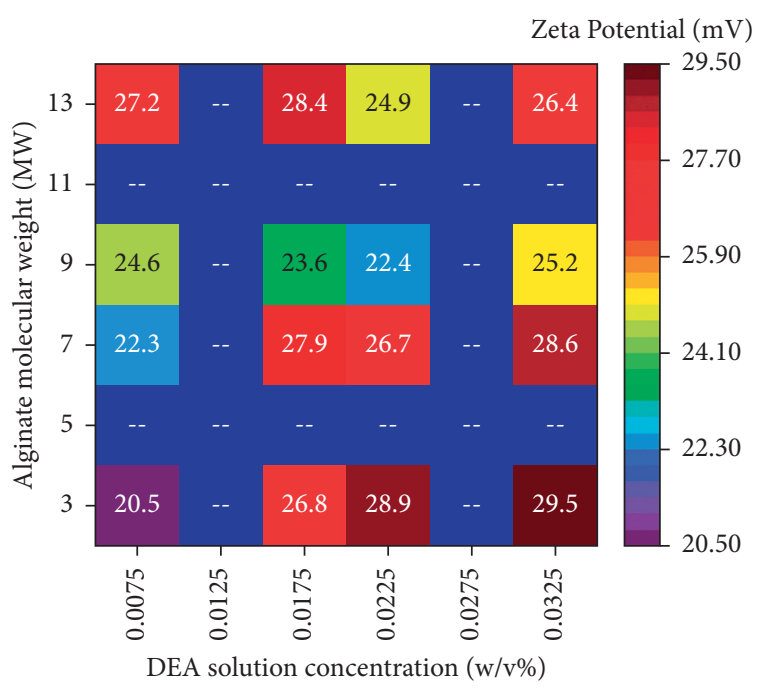

(a)

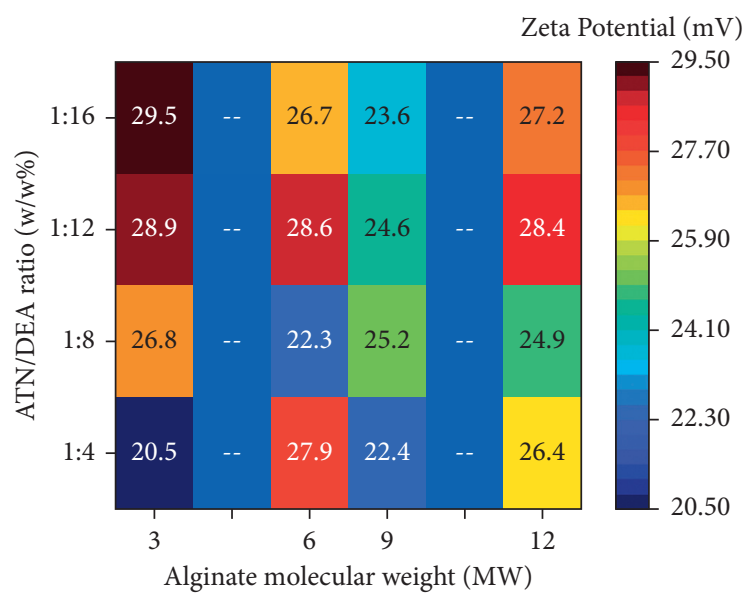

(b)

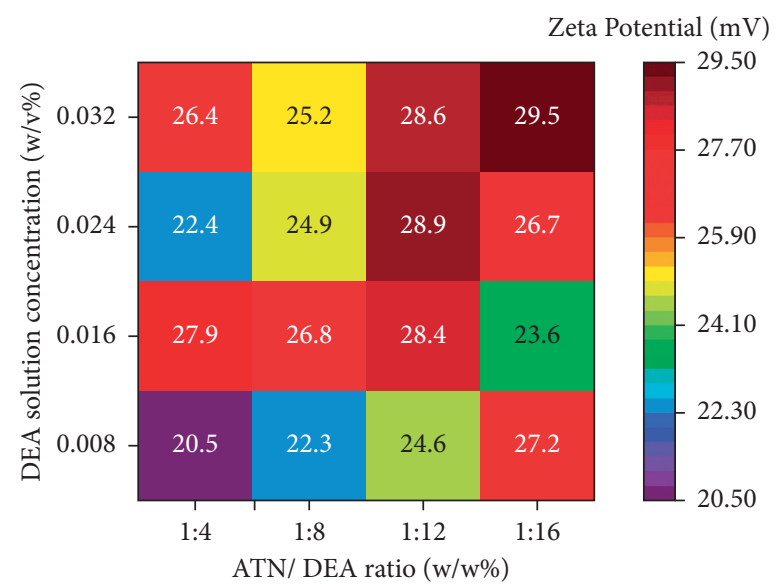

(c)

FIgURE 7: Heatmap plot analysis for zeta potential effects with the combination of factors: (a) DEA solution concentration and alginate molecular weight, (b) alginate molecular weight and ATN/DEA ratio, and (c) ATN/DEA ratio and DEA solution concentration.

by the $F$ values. In this analysis, the DEA solution concentration was extremely influenced such as $30.33 \%$, followed by the ATN/DEA ratio (28.24\%) and alginate molecular weight (18.85\%).

3.4. Regression Equation. Zeta Potential $(\mathrm{mV})=$ 25.869-2.219 DEA solution concentration (w/v \%) $0.008+0.806$ DEA solution concentration (w/v \%) 0.016-0.144 DEA solution concentration (w/v \%) $0.024+1.556$ DEA solution concentration (w/v \%) $0.032+0.556$ alginate molecular weight (MW) $3+0.506$ alginate molecular weight (MW) 6-1.919 alginate molecular weight (MW) $9+0.856$ alginate molecular weight (MW) 12-1.569 ATN/DEA ratio (w/w\%) 1:4-1.069
ATN/DEA ratio $(\mathrm{w} / \mathrm{w} \%) 1: 8+1.756 \mathrm{ATN} / \mathrm{DEA}$ ratio $(\mathrm{w} /$ w\%) $1: 12+0.881$ ATN/DEA ratio (w/w\%) $1: 16$.

Figure 7 illustrates the relationship of two parameters influence with the aid of heatmap plot analysis. Figure 7 (a) represents the associations between DEA solution concentration and alginate molecular weight. From this analysis, the maximum zeta potential occurred by involving $0.032 \mathrm{w} / \mathrm{v} \%$ DEA solution concentration and 3 molecular weight of alginate. Figure 7 (b) reveals the correlations between alginate molecular weight and ATN/DEA ratio, from this correlation the maximum zeta potential was recorded by the influence of $3 \mathrm{MW}$ of alginate and 1:16 ATN/DEA ratio. Figure 7 (c) demonstrates the connection between the ATN/DEA ratio and the DEA solution concentration. From the ATN/DEA 
ratio and DEA solution concentration, the maximum zeta potential was registered at 1:16 of ATN/DEA and 0.032 $\mathrm{w} / \mathrm{v} \%$ of DEA solution concentration.

Using three parameters and an optimization process, this experimental work was developed, helping the scientific progress of medicine preparation. A lot of technology was involved to prepare the medicine. This work was a novelty in preparing the nanohydrogel using Acacia gum-alginate for drug delivery of amethopterin in medicine production.

\section{Conclusion}

Deesterified of Acacia gum-alginate nanoparticles (DEA-AG NPs) for amethopterin (ATN) delivery was successfully carried out. The responses of particle size and zeta potential were analyzed, and the optimal parameters were obtained. Finally, the results of this experimental work were drawn as follows:

(i) From the particle size analysis, the minimum particle size was found as $148.50 \mathrm{~nm}$ by the influence of $0.008 \mathrm{w} / \mathrm{v} \%$ DEA solution concentration, 3 molecular weight of alginate, and 1:4 of w/w \% ATN/ DEA ratio. Similarly, in the zeta potential analysis, the maximum zeta potential was recorded as $29.5 \mathrm{mV}$ by relating $0.032 \mathrm{w} / \mathrm{v} \%$ DEA solution concentration, 3 molecular weight of alginate, and $1: 16 \mathrm{w} / \mathrm{w} \%$ ATN/DEA ratio.

(ii) In the particle size analysis, the optimal parameters were found as $0.008 \mathrm{w} / \mathrm{v} \%$ DEA solution concentration, 9 molecular weight of alginate, and $1: 4$ of w/w \% ATN/DEA ratio. On the other hand, the optimal parameters of zeta potential analysis were obtained as $0.032 \mathrm{w} / \mathrm{v} \%$ DEA solution concentration, 12 molecular weight of alginate, and $1: 12 \mathrm{of} \mathrm{w/}$ w \% ATN/DEA ratio.

(iii) In the particle size analysis, elevated contributions such as $55.16 \%$ were recorded by the influence of DEA solution concentration followed by $23.55 \%$ of ATN/DEA ratio and $8.33 \%$ of alginate molecular weight. Similarly, in the zeta potential analysis, the DEA solution concentration was highly influenced such as $30.33 \%$, followed by the ATN/DEA ratio (28.24\%) and alginate molecular weight (18.85\%).

(iv) Both analyses, such as particle size and zeta potential, showed that the DEA solution concentration was highly influenced by the other two parameters.

(v) This research can be extended for fine tuning of this optimal solution by further characterization with the use of morphological analysis (TEM/SEM), differential scan calorimetry, swelling, degradation, and porosity of the hydrogel.

\section{Data Availability}

The data used to support the findings of this study are included in the article. Should further data or information be required, these are available from the corresponding author upon request.

\section{Disclosure}

This research was performed as a part of the Employment Mettu University, Ethiopia

\section{Conflicts of Interest}

The authors declare that there are no conflicts of interest.

\section{Acknowledgments}

The authors appreciate the technical assistance to complete this experimental work and also draft writing from the Department of Mechanical Engineering, Saveetha School of Engineering, Saveetha Institute of Medical and Technical Sciences, Chennai. The authors thank the Department of Mechanical Engineering, College of Engineering and Technology, Mettu University, Ethiopia, for their support in draft writing.

\section{References}

[1] M. Nejatian, S. Abbasi, and F. Azarikia, "Gum Tragacanth: structure, characteristics and applications in foods," International Journal of Biological Macromolecules, vol. 160, pp. 846-860, 2020.

[2] M. Nasrollahzadeh, M. Sajjadi, S. Iravani, and R. S. Varma, "Starch, cellulose, pectin, gum, alginate, chitin and chitosan derived materials for sustainable water treatment: a review," Carbohydrate Polymers, vol. 251, Article ID 116986, 2021.

[3] B. F. Iglesias-Figueroa, E. A. Espinoza-Sánchez, T. S. Siqueiros-Cendón, Q. Rascón-Cruz, and Q. RascónCruz, "Lactoferrin as a nutraceutical protein from milk, an overview," International Dairy Journal, vol. 89, pp. 37-41, 2019.

[4] J. Ihsan, M. Farooq, M. A. Khan et al., "Synthesis, characterization, and biological screening of metal nanoparticles loaded gum acacia microgels," Microscopy Research and Technique, vol. 84, no. 4, 2021.

[5] V. V. T. Padil, E. N. Zare, P. Makvandi, and M. Černík, "Nanoparticles and nanofibres based on tree gums: biosynthesis and applications," Comprehensive Analytical Chemistry, vol. 94, pp. 223-265, 2021.

[6] J. Han, F. Chen, C. Gao, Y. Zhang, and X. Tang, "Environmental stability and curcumin release properties of pickering emulsion stabilized by chitosan/gum Arabic nanoparticles," International Journal of Biological Macromolecules, vol. 157, pp. 202-211, 2020.

[7] F. C. Bombaldi de Souza, R. F. Bombaldi de Souza, B. Drouin, K. C. Popat, D. Mantovani, and Â. M. Moraes, "Polysaccharide-based tissue-engineered vascular patches," Materials Science and Engineering: C, vol. 104, Article ID 109973, 2019.

[8] A. Koyyada and P. Orsu, "Natural gum polysaccharides as efficient tissue engineering and drug delivery biopolymers," Journal of Drug Delivery Science and Technology, vol. 63, Article ID 102431, 2021.

[9] B. J. Garg, N. K. Garg, S. Beg, B. Singh, and O. P. Katare, "Nanosized ethosomes-based hydrogel formulations of methoxsalen for enhanced topical delivery against vitiligo: formulation optimization, in vitro evaluation and preclinical assessment," Journal of Drug Targeting, vol. 24, no. 3, pp. 233-246, 2016. 
[10] E. Nazarzadeh Zare, P. Makvandi, and F. R. Tay, "Recent progress in the industrial and biomedical applications of tragacanth gum: a review," Carbohydrate Polymers, vol. 212, pp. $450-467,2019$.

[11] L. Liu, R. Jiang, and B. Lönnerdal, "Assessment of bioactivities of the human milk lactoferrin-osteopontin complex in vitro," The Journal of Nutritional Biochemistry, vol. 69, pp. 10-18, 2019.

[12] V. Raj, J.-H. Lee, J.-J. Shim, and J. Lee, "Recent findings and future directions of grafted gum karaya polysaccharides and their various applications: a review," Carbohydrate Polymers, vol. 258, Article ID 117687, 2021.

[13] L. Gali, F. Bedjou, G. Ferrari, and F. Donsi, "Formulation and characterization of zein/gum Arabic nanoparticles for the encapsulation of a rutin-rich extract from Ruta chalepensis L," Food Chemistry, vol. 367, Article ID 129982, 2022.

[14] M. Golieskardi, M. Satgunam, D. Ragurajan, M. E. Hoque, A. M. H. Ng, and L. Shanmuganantha, "Advanced 3Y-TZP bioceramic doped with $\mathrm{Al} 2 \mathrm{O} 3$ and $\mathrm{CeO} 2$ potentially for biomedical implant applications," Materials Technology, vol. 34, no. 8, pp. 480-489, 2019.

[15] Y. Zhang, C. Pu, W. Tang, S. Wang, and Q. Sun, "Gallic acid liposomes decorated with lactoferrin: characterization, in vitro digestion and antibacterial activity," Food Chemistry, vol. 293, pp. 315-322, 2019.

[16] A. I. Bourbon, J. T. Martins, A. C. P. Martins et al., "Nanoparticles of lactoferrin for encapsulation of food ingredients," in Biopolymer Nanostructures for Food Encapsulation Purposes, pp. 147-168, Academic Press, Cambridge, MA, USA, 2019.

[17] M. Velayati, H. Hassani, Z. Sabouri, A. Mostafapour, and M. Darroudi, "Biosynthesis of Se-Nanorods using gum Arabic (GA) and investigation of their photocatalytic and cytotoxicity effects," Inorganic Chemistry Communications, vol. 128, Article ID 108589, 2021.

[18] D. A. Osorio, B. E. J. Lee, J. M. Lee et al., "Cross-linked cellulose nanocrystal aerogels as viable bone tissue scaffolds," Acta Biomaterialia, vol. 87, pp. 152-165, 2019.

[19] M. Hassanzadeganroudsari, A. Heydarinasab, P. Chen, and M. Soltani, "In vitro investigation of anticancer efficacy of carboplatin-loaded PEGylated nanoliposome particles on brain cancer cell lines," Journal of Nanoparticle Research, vol. 21, no. 6, pp. 1-12, 2019.

[20] H. Munir, M. Bilal, M. I. Khan, and H. M. N. Iqbal, "Gumsbased bionanostructures for medical applications," Polysaccharides, vol. 18, pp. 385-398, 2021.

[21] B. Wang, Y. P. Timilsena, E. Blanch, and B. Adhikari, "Lactoferrin: structure, function, denaturation and digestion," Critical Reviews in Food Science and Nutrition, vol. 59, no. 4, pp. 580-596, 2019.

[22] C. S. Crowe, A. Chattopadhyay, R. McGoldrick, G. Chiou, H. Pham, and J. Chang, "Characteristics of reconstituted lyophilized tendon hydrogel," Plastic and Reconstructive Surgery, vol. 137, no. 3, pp. 843-851, 2016.

[23] K. Chen, F. Wang, S. Liu, X. Wu, L. Xu, and D. Zhang, "In situ reduction of silver nanoparticles by sodium alginate to obtain silver-loaded composite wound dressing with enhanced mechanical and antimicrobial property," International Journal of Biological Macromolecules, vol. 148, pp. 501-509, 2020.

[24] F. H. Silver and Y. P. Kato, "Synthetic collagen orthopaedic structures such as grafts, tendons and other structures," U.S. Patent, vol. 5, pp. 171-273, 1992.

[25] D. Lachowicz, A. Karabasz, M. Bzowska, M. Szuwarzyński, A. Karewicz, and M. Nowakowska, "Blood-compatible, stable micelles of sodium alginate-curcumin bioconjugate for anticancer applications," European Polymer Journal, vol. 113, pp. 208-219, 2019.

[26] S. Mallakpour and V. Ramezanzade, "Tragacanth gum mediated green fabrication of mesoporous titania nanomaterials: application in photocatalytic degradation of crystal violet," Journal of Environmental Management, vol. 291, Article ID 112680, 2021.

[27] D. Mitra, O. W. Yasui, J. N. Harvestine et al., "Exogenous lysyl oxidase-like 2 and perfusion culture induce collagen crosslink formation in osteogenic grafts," Biotechnology Journal, vol. 14, no. 3, Article ID 1700763, 2019.

[28] M. E. Hoque, J. M. Ghorban Daei, and M. Khalid, "Next generation biomimetic bone tissue engineering matrix from poly (L-lactic acid) pla/calcium carbonate composites doped with silver nanoparticles," Current Analytical Chemistry, vol. 14, no. 3, pp. 268-277, 2018.

[29] L. Bacakova, J. Pajorova, M. Bacakova et al., "Versatile application of nanocellulose: from industry to skin tissue engineering and wound healing," Nanomaterials, vol. 9, no. 2, p. 164, 2019.

[30] A. J. Ryan, W. A. Lackington, A. J. Hibbitts et al., "A physicochemically optimized and neuroconductive biphasic nerve guidance conduit for peripheral nerve repair," Advanced Healthcare Materials, vol. 6, no. 24, Article ID 1700954, 2017.

[31] P. Makvandi, Z. Baghbantaraghdari, W. Zhou et al., "Gum polysaccharide/nanometal hybrid biocomposites in cancer diagnosis and therapy," Biotechnology Advances, vol. 48, Article ID 107711, 2021.

[32] B. K. Preetha and B. Vishalakshi, "Microwave assisted synthesis of karaya gum based montmorillonite nanocomposite: characterisation, swelling and dye adsorption studies," International Journal of Biological Macromolecules, vol. 154, pp. 739-750, 2020.

[33] M. M. ElAdawy, A. E. Eissa, S. Mohamed et al., "Green synthesis and physical properties of gum Arabic-silver nanoparticles and its antibacterial efficacy against fish bacterial pathogens," Aquaculture Research, vol. 52, no. 3, pp. 1247-1254, 2021.

[34] S. Kang, Y. Xiao, X. Guo, A. Huang, and H. Xu, “Development of gum Arabic-based nanocomposite films reinforced with cellulose nanocrystals for strawberry preservation," Food Chemistry, vol. 350, Article ID 129199, 2021. 